\title{
Desarrollo urbano y forma de vida de la clase media en la ciudad de Querétaro*
}

\section{Carmen Icazuriaga Montes* *}

El presente ensayo se enmarca dentro de la temática de la relación entre desarrollo urbano y cambio cultural.

En cuanto al desarrollo urbano, el análisis se centra en datos censales referentes al crecimiento y diversificación de la estructura económica del estado y municipio de Querétaro. Se destaca la industrialización como el factor principal -a partir de 1960- y derivado de ésta el incremento del sector servicios, que ha favorecido el aumento y concentración de población de sectores medios (según ocupación) en la aglomeración urbana de la ciudad de Querétaro.

En cuanto al cambio cultural, el análisis se apoya en datos directos -obtenidos mediante una reducida encuesta aplicada en 1992- que muestran cambios en el estilo de vida de una porción de la población de la clase media urbana. Dichos cambios se refieren a las condiciones materiales de su habitat y a la percepción que tienen de la ciudad.

Una de las formas de abordar el análisis del cambio sociocultural es estudiar las modificaciones derivadas de la relación entre, los fenómenos llamados "culturales", como son el conocimiento y las ideas acerca de la realidad, los códigos de comunicación, los símbolos, los valores, las normas, etcétera -todo lo cual remite a lo que algunos autores denominan ideología o subjetividad-, 1 y lo que se denomina la estructura social, que comprende los recursos económicos y las formas de organización o instituciones a través de las cuales se cumple la interacción social, y que en sentido amplio incluye lo económico y lo político.

* El presente ensayo es un resultado parcial de la investigación sobre "Desarrollo urbano y clase media en la ciudad de Querétaro" que estoy llevando a cabo en el Centro de Investigaciones y Estudios Superiores en Antropología Social.

Los datos empíricos en los que está basado este escrito fueron obtenidos mediante observación participante, charlas informales y primordialmente a través de la aplicación de una encuesta. Esto se efectuó en una primera etapa que fue parte del proyecto titulado "Sectores medios en tres ciudades: México, Guadalajara y Queréta ro" de dirección colectiva de González De la Rocha, Esteinoú Madrid e Icazuriaga Montes y que se realizó por convenio cresas-Conacyt.

Para una segunda etapa de búsqueda y sistematización de datos censales y de otros estudios sobre la aglomeración urbana, el municipio y el estado de Querétaro, conté con el apoyo financiero de la Fundación Japón en México.

** CIESAS.

1 Para una exposición sintética de la discusión acerca de cultura y superestructura en relación con los fines analíticos de desarrollo y cultura, remito a Arizpe (1989: 25-31). 
En el presente ensayo, parto de la forma de abordar la relación entre desarrollo y cultura, estableciendo para fines analíticos, por un lado, lo que se conceptualiza en el nivel de las estructuras como desarrollo urbano y, por otro, lo que se considera al nivel de la cultura, como forma o estilo de vida, limitándome a las condiciones materiales, algunas conductas y ciertas valoraciones $^{2}$ que expresan a un sector de la población categorizado como clase media.

Por desarrollo urbano considero el incremento en número y densidad de habitantes en un área y la expansión de ésta, la existencia de infraestructura y equipamiento urbanos adecuados según las innovaciones que van surgiendo (drenaje, luz, agua, red de telecomunicación: telégrafo, teléfono, fax, radio, televisión, etcétera), la diversificación de los servicios (comerciales, educativos, de salud, de diversión, etcétera) y la complejización de la estructura económica urbana.

En cuanto al estilo de vida, o forma de vida, utilizo un concepto de Bordieu quien lo define como el conjunto de prácticas culturales que conforman una serie de hábitos o costumbres, que son: "características auxiliares que, a modo de exigencias tácitas pueden funcionar como principios de selección o de exclusión reales sin ser jamás formalmente enunciadas" (Bordieu, 1990: 17) y que diferencian a las clases sociales. Es decir, que para entender las diferencias entre clases sociales no es suficiente establecer la forma en que participan en la estructura de producción, sino que "también constituyen el modo de ser de una clase o fracción de clase, el barrio en que viven sus miembros, la escuela a la que envían a sus hijos, los lugares a los que van de vacaciones, lo que comen y la manera en que lo comen..." (Bordieu, 1990: 17). En esta línea de pensamiento se sitúa también Giddens (1983) quien afirma que en términos de la teoría de la estructuración no es suficiente referirse a la clase en términos de estructura de relaciones como si no tuviese, contenido, ya que "si la clase se convierte en una realidad social, esta situación debe manifestarse en la formación de pautas comunes de conducta y de actitud" (Giddens, 1983: 125). ${ }^{3}$

2 Estos aspectos ya los he desarrollado parcialmente en otras ponencias, véase Icazuriaga, 1992 y 1993, y se puede ver también en Estrella Hernández, 1992.

${ }^{3}$ Giddens afirma que existe una: "distinción inicial entre 'reconocimiento de clase' (class awareness) y 'conciencia de clase'. Podemos decir que en tanto que la clase es un fenómeno estructurado, existirá la tendencia a un reconocimiento común y a aceptar unas actitudes y creencias similares, ligadas a un estilo de vida común, entre los miembros de la clase. El reconocimiento de clase en el sentido en que se emplea el término aquí, no implica una aceptación de que esas actitudes 
Para fines operativos conceptualizo a la clase media como aquélla formada por los individuos, y las familias que dependen económicamente de éstos, que llevan a cabo tareas no manuales, tanto en el sector secundario, es decir de la actividad industrial, como en el sector terciario del comercio, el transporte y los servicios. 4

\section{Industrialización, desarrollo urbano y crecimiento de los sectores medios de Querétaro}

El desarrollo urbano moderno, es decir, el proceso de urbanización dentro del sistema capitalista, ha ido a la par históricamente con el proceso de producción industrial y las necesidades asociadas a éste. 5 La interrelación industrialización-urbanización se ha dado en el caso de la ciudad de Querétaro, pues ésta ha tenido un desarrollo creciente, a partir de la década de los cuarenta, debido a la localización de industrias de transformación de materias agropecuarias y de otras, de producción de bienes de consumo, vinculadas primordialmente a la economía regional.

A partir de los años sesenta se produce un cambio en el tipo de empresas, instalándose industrias de bienes intermedios, algunas de las cuales iniciaron el nuevo proceso de fragmentación en la organización de la producción industrial. ${ }^{6}$ En este nuevo proce-

y creencias signifiquen una afiliación particular a una clase o de que existan otras clases caracterizadas por actitudes, creencias y estilos de vida diferentes; la conciencia de clase por el contrario, tal y como empleo esta noción, implica ambas. La diferencia entre reconocimiento de clase y conciencia de clase es de índole fundamental, porque el primero puede adoptar la forma de una negación de la existencia o de la realidad de las clases (sic). Así, el reconocimiento de clase de la clase media, en la medida en que implica creencias que premian la responsabilidad y los logros individuales, es de este orden" (Giddens, 1983: 126).

4 Véase Claudio Stern, "Notas para la delimitación de las clases medias en México", en Loaeza y Stern (coords.), 1990.

5 Castells (1986) señala que aun el 'modelo de desarrollo informacional', que ha llevado a una reorganización del espacio y el surgimiento de la ciudad informacional, está inextricablemente entrelazado con el modelo de desarrollo industrial.

6 Para mayor detalle de este proceso de industrialización y crecimiento urbano de la ciudad de Querétaro remito a los trabajos de Munguía Huato (1988), para el desarrollo urbano desde el siglo pasado hasta los años setenta; a los trabajos de García Peralta (1988) para 1960 a 1980, y al de González Gómez y Martner Peyrelongue (1990) que analizan el periodo de 1940 a 1990 y enfatizan los procesos de restructuración espacial debido a la fragmentación en la organización de la producción.

Para datos complementarios a nivel de la región y enmarcados dentro del contexto nacional, remito al trabajo clásico de Unikel, Ruiz y Garza (1978) que hace referencia a datos hasta 1970 y para datos referentes hasta 1980, véase Garza (1992). 
so de instalación industrial, adecuado a los requerimientos de la organización económica más amplia de nivel nacional y vinculado con la producción en el nivel internacional, se da un nuevo proceso de restructuración territorial en el estado de Querétaro, que hace surgir el corredor industrial San Juan del Río-Querétaro (que abarca, además de esos dos municipios, a los de El Marqués, Villa Corregidora y Pedro Escobedo). Dentro de este nuevo proceso de relocalización espacial de la industria dentro del estado, a partir de 1976 (González Gómez y Martner Peyrelongue, 1990) el municipio de Querétaro deja de ser el principal lugar para la instalación de industrias; éstas aparecerán en municipios aledaños, con lo que la aglomeración urbana de la ciudad de Querétaro, con su zona conurbada de municipios vecinos, sigue siendo el principal centro de atracción de inmigrantes no sólo para la población del mismo estado, sino también de otros (véanse los cuadros 1 y 2).7

CUADRO 1

Población del estado de Querétaro y su capital, 1900-1990

\begin{tabular}{lrrrrrr}
\hline Año & 1900 & 1910 & 1921 & 1930 & 1940 & 1950 \\
\hline $\begin{array}{l}\text { Estado } \\
\text { Ciudad }\end{array}$ & 232389 & 244663 & 220231 & 234058 & 244737 & 286238 \\
& 33152 & 33062 & 30073 & 32585 & 33629 & $49440^{\mathrm{d}}$ \\
\hline Año & & 1960 & 1970 & 1980 & 1985 & 1990 \\
\hline Estado & & 355045 & 485523 & 739605 & 882735 & 1051235 \\
Ciudad & & 69058 & $116233^{\mathrm{d}}$ & 259000 & 340000 & 435424
\end{tabular}

Nota: La población de estas áreas urbanas está formada por la registrada en el censo -denominada ciudad central- más localidades periféricas que se consideraron integradas físicamente a la primera, con fundamento en su contigüidad y relativa accesibilidad a la ciudad central.

Fuentes: Elaboración a partir de: Luis Unikel et al., 1978: 377-380; Munguía Huato, 1980: 29; Manual de Estadísticas Básicas, Edo. de Querétaro, 1985; González Gómez y Martner Peyrelongue, 1990: 26, y XI Censo General de Población y Vivienda, 1990, Datos por localidad (Integración territorial), pp. 37, 40-41 y 43, INEGI, México, 1992.

${ }^{7}$ En relación con la elaboración de los cuadros censales, agradezco la ayuda de Esperanza Estrella Hernández y de Agustín Icazuriaga Z. 


\section{CUADRO 2}

Concentración de población por municipios, en la aglomeración de la ciudad de Querétaro, 1990

\begin{tabular}{lrcrrr}
\hline & & & Población & \\
\cline { 2 - 5 } & & & $\begin{array}{c}\text { Porcentaje } \\
\text { que vive en } \\
\text { localidades }\end{array}$ & $\begin{array}{r}\text { Porcentaje } \\
\text { de la } \\
\text { aglome- } \\
\text { ración }\end{array}$ \\
\hline Cd. de Querétaro & 385503 & 385503 & 100.00 & 88.47 \\
Otras localidades & 70955 & $10603^{a}$ & 14.94 & 2.43 \\
Mpio. de Querétaro & 456458 & 396106 & 86.78 & $\mathbf{9 0 . 9 0}$ \\
Mpio. de Corregidora & 43775 & $30443^{b}$ & 69.54 & 6.99 \\
Mpio. El Marqués & 55258 & $9180^{c}$ & 16.61 & 2.11 \\
Totales & 555491 & $435729^{d}$ & 78.44 & 100.00 \\
Estado & 1051235 & 435729 & 41.45 & \\
\hline
\end{tabular}

Fuente: Elaborado con base en: "Datos por localidad (integración territorial)", en XI Censo General de Población y Vivienda, 1990, pp. 37, 40-41 y 43, México, INEGI, 1992.

Notas:

a. Esta cifra la componen las localidades de:
San Pedro Mártir
1722 habitantes
Sta. María Magdalena $\quad 5198$ habitantes
Tlacote El Bajo 3683 habitantes
Total
10603 habitantes

b. Esta cifra la componen las localidades de:
El Pueblito
23022 habitantes
Colinas del Bosque
307 habitantes
Los Olvera
2383 habitantes
San José de los Olvera
3794 habitantes
Tejeda
937 habitantes
Total
30443 habitantes

c. Esta cifra la componen las localidades de:
La Cañada
7815 habitantes
Saldarriaga
1365 habitantes
Total
9180 habitantes

d. Graizbord da la cifra de 497477 habitantes para la Zona Metropolitana de la Ciudad de Querétaro (véase Cambios territoriales en México: exploraciones recientes, Delgado y Villarreal (coord.), México, uam Xochimilco, 1992, p. 204).

Observaciones:

Las localidades consideradas como "conurbadas" se ubican en un radio de $12 \mathrm{~km}$ a partir del centro de la ciudad de Querétaro, mismo en el que circula el transporte urbano y suburbano en horario corrido de las 6:00 a las 21:30 horas.

Otras localidades con mayor población, como Santa Rosa Jáuregui (11 798 habitantes) y Juriquilla ( 1508 habitantes), cuentan con servicio de transporte que debe abordarse en la Central Camionera, y en Provincia Juriquilla (143 habitantes) sus habitantes utilizan autos privados. 
A partir de la década de los ochenta, se registra un crecimiento asociado al desarrollo industrial del sector terciario, que se concentra en el municipio de Querétaro y consecuentemente en la ciudad (véanse los cuadros 3 y 4). Este desarrollo de la estructura económica implica un incremento de los sectores medios, que se ocupan hoy día tanto en el sector terciario como en el sector secundario (cuadro 5), lo cual contrasta con lo que señalaba Whiteford (1964) en su estudio sobre la ciudad de Querétaro en 1958. Ésta es que a diferencia de la clase media de las ciudades medias de Estados Unidos, en donde la industrialización había hecho surgir diversas ocupaciones "de cuello blanco" con régimen asalariado, en la ciudad de Querétaro, debido a la falta de un número suficiente de industrias que demandaran técnicos y profesionistas para ser empleados por ellas, la clase media casi no contaba con miembros de cuello blanco y estaba predominantemente compuesta por comerciantes y profesionistas que trabajaban por cuenta propia.

Paralelamente al desarrollo económico de la ciudad de Querétaro, aflora el incremento de la población demandante de vivienda,8 infraestructura y equipamiento urbanos, los que se constituirán en elementos de diferenciación de la población en el espacio.

Expansión del área urbana y segregación socioespacial

A mediados de la década de los cincuenta del presente siglo, con la lotificación y venta de terrenos en la colonia Cimatario, la Jardines de Querétaro, y del fraccionamiento Club Campestre, el

CUADRO 3

PEA en el municipio de Querétaro por sectores económicos, 1960-1990

\begin{tabular}{lrrrr}
\hline & \multicolumn{4}{c}{ Años } \\
\cline { 2 - 5 } Sectores & 1960 & 1970 & 1980 & 1990 \\
\hline Primario & 39.1 & 18.0 & 6.4 & 3.7 \\
Secundario & 25.2 & 33.0 & 32.8 & 37.0 \\
Terciario & 35.5 & 42.0 & 38.1 & 57.0 \\
No especificado & 0.2 & 7.0 & 22.7 & 2.3 \\
\hline
\end{tabular}

Fuente: Elaborado con base en: García Peralta, 1988: 19 y XI Censo General de Población y Vivienda 1990, Querétaro, INEGI, 1992.

8 Véase el incremento de número de viviendas en el municipio de Querétaro; de 1950 a 1980 en García Peralta, 1988: 26. 


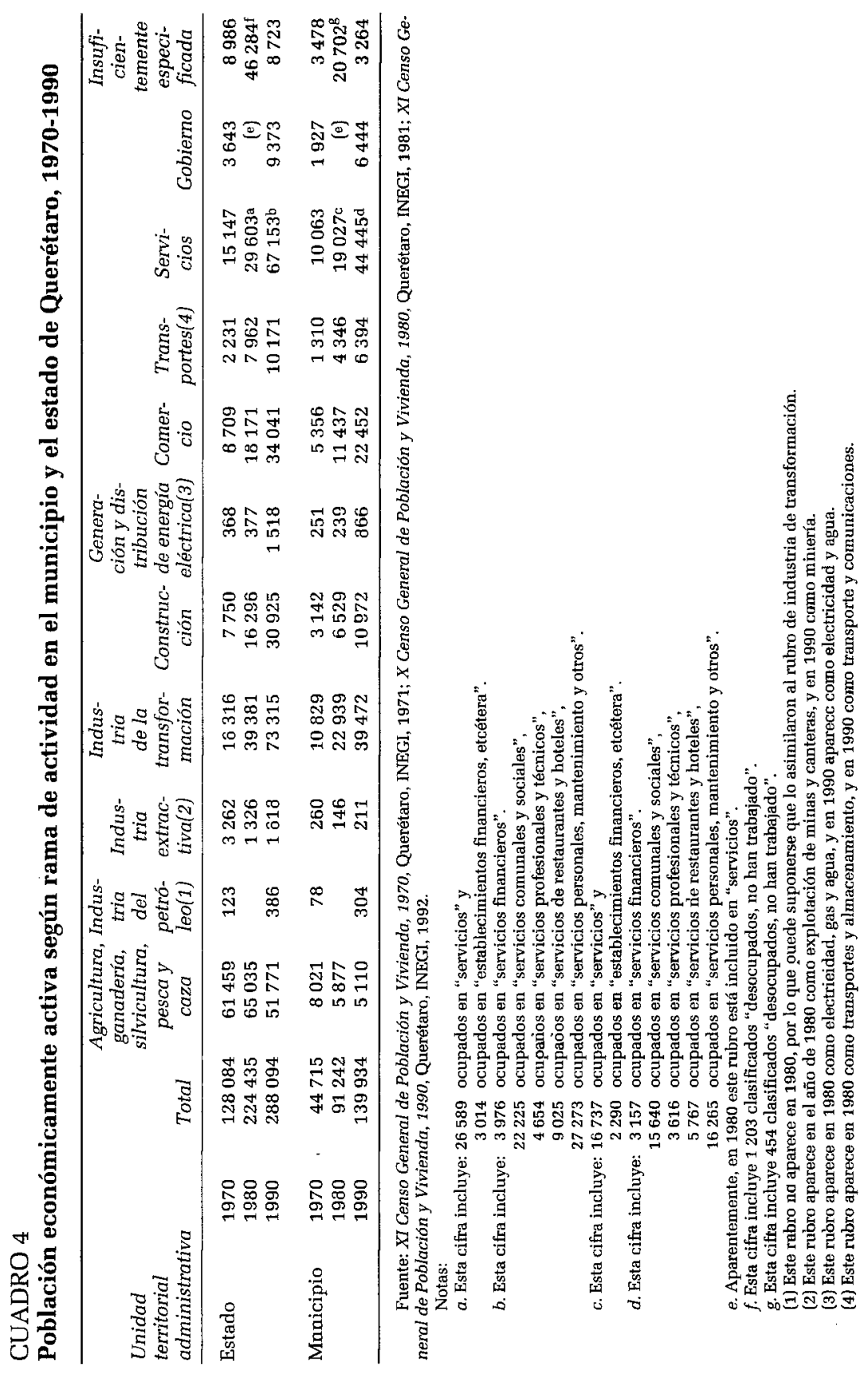




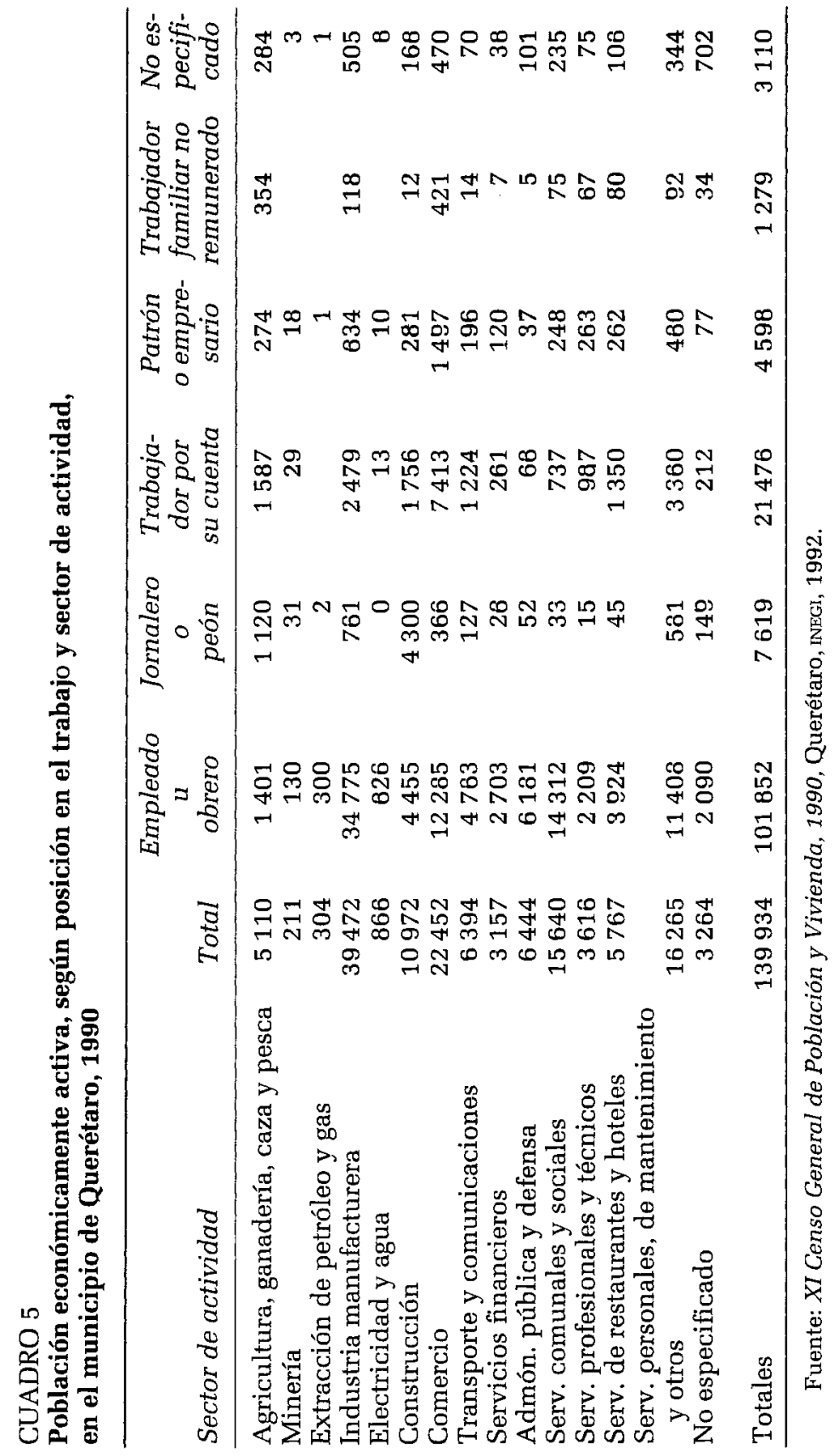


más exclusivo de entonces, se intensifica como señalan González y González (1992: 153) "la construcción de viviendas nuevas claramente diferenciadas por estratos socioeconómicos." En este caso para las capas de "ingresos elevados". Pero es en la segunda mitad de la década de los años setenta cuando

[...] la ciudad experimenta su mayor cambio estructural, ya que para 1968 surge el fraccionamiento Jurica, el de mayor extensión en toda la historia de la localidad, mismo que para el momento de su creación se encontraba fuera de los límites del área urbana... Asimismo, surgen otros fraccionamientos importantes, en su mayoría destinados a sectores socioeconómicos medios y altos, promovidos por inmobiliarias (Chavarría y Sánchez, 1992: 84-85).

Para la etapa 1970-1980:

la mancha urbana presentó su mayor expansión... La expansión de la ciudad durante esta etapa se presenta hacia la zona agrícola del Bajío (al poniente de la ciudad) por constituir propiedad privada perteneciente a ex haciendas... los asentamientos irregulares que surgieron durante este periodo se presentaron principalmente sobre tierras ejídales en poblados del municipio próximos a la mancha urbana, lo cual influyó también en la expansión del área urbana de la ciudad. Los principales poblados fueron Casa Blanca, Menchaca, Bolaños y San Pablo: dichos asentamientos se iniciaron a partir de 1972 (Chavarría y Sánchez, 1992: 86 y 94).

\section{Para 1980-1990:}

[...] la expansión de la mancha urbana disminuye en relación al periodo anterior...., esto como consecuencia de que la actividad inmobiliaria disminuye sus acciones, así como también el sector industrial se estabiliza, por lo cual ya no se presenta el acelerado crecimiento experimentado en la década anterior (Chavarría y Sánchez, 1992: 96).

Asimismo, estos autores señalan (1992) que, si bien la expansión del área urbana en cuanto a número de hectáreas fraccionadas por agentes privados es menor que durante la década anterior, se intensifica en el uso habitacional del suelo, y la ocupación y venta ilegal de tierra, lo que empieza a adquirir importancia significativa en el proceso de urbanización de la ciudad; además

[...] lo que es relevante en este lapso, es la tendencia a la conurbación de poblados cercanos a la ciudad, [que] si bien físicamente no están fusionados sí lo han hecho de manera funcional como El Pueblito (perteneciente al municipio de Villa Corregidora), la Cañada, Santa 
Rosa Jáuregui, Santa María Magdalena y San Antonio de La Punta... Un hecho que refleja este fenómeno es que la mayor parte de los asentamientos irregulares que surgen en esta etapa se localizan fuera del área urbana (Chavarría y Sánchez, 1992: 97 y 100).

En síntesis, podemos decir que la expansión del área urbana se ha debido primordialmente a la construcción de viviendas y en segundo lugar a la construcción de parques y zonas industriales. La adecuación de zonas para uso residencial, y en algunos casos la construcción de viviendas, ha sido realizada mayoritariamente, desde mediados de la década de los cincuenta hasta la fecha, por inmobiliarias y fraccionadores que la destinan para estratos medios y altos de la población. En cambio, la construcción de zonas residenciales para los "sectores populares" ha sido efectuada por el estado, de manera intermitente, a partir de la década de los sesenta y representa una menor proporción en el área urbana. Sin embargo, a partir de la década de los setenta, y sobre todo en la de los ochenta, se va incrementando la vivienda popular de autoconstrucción sobre terrenos ejidales. Estas zonas de ocupación ilegal carentes de infraestructura completa y equipamiento urbano suficiente, son ya significativas en extensión dentro de la aglomeración urbana, pero no se cuenta con números precisos sobre hectáreas ocupadas, debido a su carácter de "zonas urbanas irregulares".

Las diferentes etapas de construcción de vivienda, referidas al desarrollo económico de la ciudad y realizadas por diferentes agentes, han incidido en la segregación socioespacial de la ciudad, en la cual se presentan ya características que podrían considerarse como de metropolización. Una de éstas es la conurbación de pueblos, que genera distintos tipos de uso, densificación y segregación en el espacio, y origina distintos ritmos y estilos de vida en el conjunto de la zona metropolitana.

El espacio habitacional de una fracción de la clase media urbana

La vivienda para población de ingresos medios es, según observación directa y análisis censal, la mayoritaria en términos de extensión dentro del área urbana, aunque quizás no la que aloje al mayor número de población, ya que en las zonas populares se registra una densidad mucho mayor. ${ }^{9}$ 
Hoy día se puede observar de manera directa, la diferenciación notoria de zonas residenciales con base en la infraestructura y equipamiento urbanos, así como al tamaño y calidad de la vivienda. Ello contrasta con lo que señala Whiteford (1964) para 1958, antes del crecimiento industrial sostenido, cuando en relación con la distribución espacial de las diferentes clases sociales en la ciudad de Querétaro, no podía hablarse de zonas residenciales exclusivas, de acuerdo con cada una de las clases (alta, media y baja), sino que en general había una mezcla de las casas de los miembros de las diferentes clases sociales en el área urbana de esa época; aunque sí existían dos zonas que se consideraban de clase baja (el barrio de San Francisquito y la zona de El Tepetate), y otras de clase media, pero en ningún caso, exclusivas para dichas clases. Las casas de las familias de clase alta, por lo general se localizaban en el centro -en las calles adyacentes a la plaza- que era el mejor lugar para vivir, pues contaba un elevado estatus por ser en donde se localizaban y concentraban los edificios de gobierno y religiosos más importantes de la ciudad. Sin embargo, también en el centro se localizaban vecindades donde vivían familias de clase baja. Dos nuevas secciones (colonia Cimatario y Club Campestre) empezaban a construirse en aquella época, con casas de estilo moderno que se diferenciaban del estilo colonial predominante en la ciudad. Hoy, en cambio, prolifera el estilo arquitectónico moderno y hasta el posmoderno, y se construyen más fraccionamientos y plazas comerciales que son los centros de moda para ir de compras y hasta para pasear.

La selección de vivienda y su localización no se basan exclusivamente en las preferencias individuales; éstas están limitadas por el mercado del suelo y de la vivienda misma.10 De esta manera, el acceso al suelo, la cantidad, calidad y diversidad de la infraestructura y del equipamiento urbanos, y las características de la vivienda, son todos factores que confluyen en la segregación socioespacial, la cual origina grupos más o menos homogéneos de población que viven concentrados en zonas específicas de la ciudad. ${ }^{11}$ Estas

${ }^{10}$ Harvey (1985: 123-124) señala que:

En lugar de, por consiguiente, considerar la diferenciación residencial como el producto pasivo de un sistema de preferencias basado en las relaciones sociales, tenemos que verlo como una influencia intermediadora integral en los procesos por los cuales las relaciones de clase y las diferenciaciones sociales son producidas y sostenidas. Es claro, aun en esta etapa preliminar del análisis, que la teoría de la diferenciación residencial tiene mucho que ofrecer así como mucho que ganar, de la integración cabal con la teoría social general [traducción de la autora].

11 Para mayor fundamentación teórica de este punto véase "Residential Differentiation and the Social Order" de Harvey (1985). 
zonas tienen características diferenciales en equipamiento urbano (comercios, escuelas, parques y lugares de esparcimiento, etcétera) e infraestructura (pavimentación, drenaje, agua, luz, teléfonos, etcétera), lo cual incide en los estilos de vida de la población. 12

El grupo de población al que haré referencia en relación con su espacio habitacional el cual conforma parte de su estilo de vida, es de una fracción de la clase media citadina que habita en las colonias: Burócrata, Álamos 3a. sección, Niños Héroes, Cimatario y Jardines de Querétaro. Dichas colonias fueron seleccionadas con base en los criterios de cantidad y calidad de la infraestructura y el equipamiento urbanos, características de la vivienda (extensión del terreno y costo de los materiales de construcción) y fecha de creación de la colonia, ubicándolas dentro de un continuum de estratificación. Ello permite abarcar más fracciones de clase y ponderar sus diferencias-similitudes, y cubrir a futuro uno de los objetivos de la investigación que estoy desarrollando, que es analizar, si como dicen Pincon-Charlot, Preteceille y Rendu (1986), las características diferenciales del espacio urbano en el cual se desarrollan las prácticas de consumo de las diferentes clases sociales constituyen un elemento indispensable para el análisis de la producción y la reproducción de las mismas. ${ }^{13}$

La información fue obtenida mediante encuestas a 93 unidades domésticas (UD) de las colonias antes mencionadas. 14 Dichas colonias fueron clasificadas como de clase media, con base en el espacio residencial, según los criterios antes mencionados, comparándolas con otras del área urbana; constatándose después de levantadas las encuestas, con base en ingresos y ocupaciones,

12 Vale aquí señalar lo que afirman Pincon-Charlot, Preteceille y Rendu (1986: 108): "En su conjunto, el sistema de los equipamientos colectivos refuerza las desigualdades de ingreso, de tiempo, de acceso a la cultura, en el más amplio sentido, ligados a la ubicación dentro del proceso de trabajo y las relaciones de producción" [traducción de la autora].

13 Aunque también señalan Pincon-Charlot, Preteceille y Rendu (1986: 112) que:

En efecto, las prácticas de consumo, en sentido amplio, de las diferentes clases, fracciones de clase, estratos sociales, no son determinadas de manera mecanicista y unívoca por las condiciones urbanas de estas prácticas. Viejo debate sobre las ilusiones del reformismo urbano, que creyó que se "podía cambiar la vida" cambiando solamente la ciudad. Las prácticas son el resultado de procesos complejos donde intervienen, al mismo tiempo que las condiciones urbanas, puntos negligibles por lo tanto, todas las condiciones inmediatamente determinadas por el lugar dentro del proceso de trabajo (relación salarial y nivel de salario, calificación, condiciones, horarios y lugar de trabajo, etcétera...), aquellas que contienen a las relaciones familiares, así como la huella material y cultural de las condiciones pasadas (patrimonio) [traducción de la autora].

14 Agradezco la participación en la primera etapa de la investigación a Raquel González Loyola, Norma Hernández Hernández, Mercedes Guerrero Morales y Sulima García Falconi, estudiantes de la Universidad Autónoma de Querétaro. 
que, efectivamente, las unidades domésticas seleccionadas correspondían a dicho sector o clase. La muestra no fue elaborada de manera representativa estadísticamente, sólo se aplicaron mayor o menor número de encuestas según la cantidad de viviendas en la colonia.

Condiciones de vida y valoraciones que expresa la población estudiada

El tipo predominante (53\%) de la unidad doméstica es de familia nuclear compuesta por el padre, la madre y dos o tres hijos(as) solteras. Cerca de una cuarta parte $(24 \%)$ se compone de unidades domésticas donde viven, además de la familia nuclear, algún otro pariente, ya sea la madre del ama de casa, la nuera, o nietos, y con menor frecuencia, hermanas del ama de casa o sobrinos. Aproximadamente otra cuarta parte $(23 \%)$ la forman unidades domésticas donde no existe el padre-esposo, y las mujeres, en su mayoría viudas y con menor frecuencia separadas o divorciadas, cubren el papel de jefas de familia.

Las edades de estas personas van desde uno hasta 87 años, pero poco más de la mitad (52.7\%) tienen de uno a 25 años, lo que nos indica una población joven de hijos(as) solteros, que salen del hogar paterno hasta que se casan; muy pocos lo hacen por motivos de estudio o de trabajo, que generalmente encuentran fuera de la ciudad, y contados son los casos en que el hijo o la hija se va para vivir solo(a). Más de la mitad de los hijos o hijas (62\%) se dedica únicamente al estudio, un número significativo se encuentra estudiando licenciaturas y hasta posgrados, en coincidencia con la valoración que expresan los padres y las madres sobre la importancia de que los hijos estudien para valerse por sí mismos y hacer frente a la crisis económica que se vive en el país. La otra porción (38\%) de hijos(as) solteros que viven en el hogar se ocupa en ayudar a las labores domésticas, sobre todo las mujeres, o bien trabajan para obtener un ingreso, el cual gastan exclusivamente en ellos mismos para compra de ropa, zapatos o en diversiones, y no contribuyen a los gastos de mantenimiento de la vivienda o de alimentación.

En relación con la composición de la unidad doméstica y por tanto del tipo de habitantes, se entienden mejor las características de la vivienda de este sector de población. La casi totalidad de la unidades domésticas habita en casas unifamiliares, sólo $7.5 \%$ vive en departamentos, pues cuando se crearon las colonias donde residen, el tipo de vivienda departamental era inusual. $78 \%$ de 
dichas casas es propiedad del jefe de familia o de ambos cónyuges; $16 \%$ son casas rentadas, y $6 \%$ prestadas por algún familiar. La mitad de los que son propietarios adquirieron su casa mediante el ahorro, $14 \%$ la adquirió mediante préstamo bancario; $15 \%$ mediante préstamo del estado (generalmente para viviendas de interés social); $7 \%$ mediante préstamos en el trabajo; $6 \%$ por herencia, y $3 \%$ mediante préstamo de parientes; pero en la mayoría de los casos se presentan dos de estas formas combinadas, siendo lo más común ahorros y préstamo bancario. Lo anterior contrasta con lo que Whiteford señala para 1958, cuando muy pocos miembros de la clase media eran propietarios de la casa donde vivían, aunque sí lo eran los de la clase media alta. En cambio, hoy día, la mayoría de los jefes de familia de la clase media en su conjunto son propietarios de su casa, lo que significa que el gasto destinado a vivienda representa solamente un porcentaje de $5-30 \%$ del gasto total de la unidad doméstica, ya que la mayoría de las uD no gastan en renta sino en mantenimiento y servicios (agua, luz, gas, teléfono) de la vivienda. Además, en la actualidad encontramos que en un número significativo de las UD, el padre y (o) la madre son además dueños de un terreno o de otra vivienda, y los consideran como patrimonio para sus hijos. Podemos concluir sobre este aspecto, que la clase media queretana ha logrado, gracias al desarrollo urbano, incrementar su patrimonio y consecuentemente aumentar su nivel de vida al destinar a otros rubros el gasto que anteriormente se destinaba a renta de la vivienda. Los propietarios de las actuales viviendas que son originarios de la ciudad de Querétaro, vivían anteriormente, casi todos, en colonias que se ubican en estratos más bajos, con lo que se puede afirmar que estos jefes de familia de sectores medios han tenido una movilidad social ascendente, que se manifiesta en primera instancia por la zona residencial que ocupan hoy día.

El número de cuartos y tipo de materiales de la vivienda se relacionan no sólo con la diferencia en el nivel de ingreso, sino también en cuanto a la fecha de construcción que corresponde a un estilo arquitectónico y de funcionalidad. Tenemos así, que las viviendas visitadas fueron construidas desde la década de los cuarenta hasta hace apenas cinco años, y por lo tanto existen matices de diferenciación entre ellas no sólo en cuanto al deterioro, sino a los estilos, pero en general se puede decir que hay un prototipo de vivienda de clase media de la ciudad de Querétaro, que sería el siguiente: vivienda de dos pisos, construida en 200 y hasta $300 \mathrm{~m}^{2}$ con tres recámaras, dos baños, cocina, sala-comedor, un cuarto extra para usos diversos, jardín pequeño y (o) patio, garage para uno o dos vehículos. Los materiales de que están hechas son 
duraderos: ladrillo o tabique, varillas, cemento, fierro y los recubrimientos u ornamentación varía según el estilo arquitectónico de la época.

La mayoría ( $82 \%$ ) de las UD cuentan con automóvil (30\% tienen hasta dos automóviles y $7 \%$ hasta tres o cuatro), y dentro de las finalidades que expresan las amas de casa o los esposos, para realizar un ahorro, están en tercer lugar el de la compra de un vehículo (antecedido por motivos como el de tener un fondo para imprevistos y el de utilizarlo como base para solicitud de créditos). En este aspecto, podemos afirmar lo que Douglas e Isherwood (1990: 74) plantean acerca de que: "En lugar de suponer que los bienes son fundamentalmente necesarios para la subsistencia y el despliegue competitivo, asumamos que son necesarios para hacer visibles y estables las categorías de una cultura". El automóvil se ha convertido para la clase media en un elemento de estatus que los diferencia de las clases inferiores, así también los aparatos electrodomésticos (lavadora-secadora de ropa, aspiradora de polvo, refrigerador, batidora, tostador de pan, horno eléctrico, horno de microondas, abrelatas eléctrico, multiprocesadora de alimentos, extractor de jugos, aspiradora, televisión a color, computadora, videograbadoras, antenas parabólicas, sistemas modulares, entre otros) se han convertido en elementos necesarios, más que por su uso intensivo, por ser considerados como elementos de estatus y modernidad ( $v$. gr. el horno de microondas se utiliza para recalentar, pues se sigue cocinando preferentemente en la estufa de gas).

Los informantes que migraron a la ciudad de Querétaro, llegaron a ésta desde fecha tan temprana como 1917, y los más recientes, hace cinco años. Es a partir de los años sesenta que se registra un incremento de los inmigrantes de la muestra, y en los años setenta se incrementa aún más que en la década anterior. Todos los que inmigraron, así como los originarios de Querétaro, se manifestaron (97\%) contentos de vivir en esta ciudad. Algunos expresaron el deseo,-aunque no proyecto- de emigrar a otra ciudad por la razón primordial de que su familia residía allá. Opinan, en general, que les gusta vivir en la ciudad de Querétaro porque consideran que se caracteriza por una buena calidad de vida ya que ofrece variados y diversos comercios y servicios, y porque está bien ubicada, pues es fácil trasladarse a otros sitios. En cuanto a la colonia donde viven, $90 \%$ de los que respondieron les agrada porque estiman que está bien ubicada y porque es segura y tranquila, en segundo término, mencionaron que les agradaba por el estilo de las casas (modernas), porque no están junto a colonias populares y debido a que tienen "buenos vecinos que son gente como ellos". Los que manifestaron querer cambiarse de colonia dieron como 
motivos el exceso de ruido debido al incremento del tráfico en la colonia y la disminución de la seguridad (más robos).

Reconocen todos estos informantes que ya empiezan a surgir problemas urbanos; entre los principales citaron: la creciente escasez de agua, la deficiencia de vialidades por el creciente tráfico de vehículos y la falta de seguridad pública (referida sobre todo a robos y asaltos). Enfatizan tres desventajas de la ciudad que son: la falta de agua, la insuficiencia del drenaje y la deficiente vialidad; los originarios de Querétaro señalan también la sobrepoblación. Todos los informantes atribuyen estos problemas al crecimiento poblacional debido principalmente, a la instalación de industrias y, en segundo lugar, a la descentralización de la ciudad de México. A pesar de que reconocen que existe algún problema urbano, los miembros de $\mathbf{8 0} \%$ de las UD declararon no querer irse a vivir a otra ciudad y entre los que sí quieren salir destacan los que son originarios de Querétaro, cuya motivación afirman para emigrar es la de mejorar su calidad de vida.

Cabe mencionar lo que señalan Leñero y Fernández (1983: 81), en su estudio sobre la ciudad de Querétaro en 1983, respecto a los miembros de la "clase ocupacional" de los profesionales y ejecutivos, a los que ubican en la clase media y quienes:

[...] se muestran finalmente como poco críticos al crecimiento de la ciudad y menos deseosos de vivir en otra urbe. Aunque también son los más interesados por los problemas de sus vecinos, son los que plantean una mayor satisfacción personal sin una participación solidaria y de sentido social. [...] Son, de hecho protagonistas clave en el desarrollo de una modernidad que sigue, en su sentido, la tónica que le imprime este sector a su propia vida, erigida tácita o explícitamente -aunque extralógicamente- como modelo de las formas de vida de la ciudad moderna.

A pesar de que los informantes declararon como uno de los motivos de que les guste su colonia el que los residentes son "gente como ellos", casi no se dan relaciones entre los vecinos. Para solicitar cualquier tipo de ayuda (sea en dinero, acompañamiento, realización de un trabajo, de información, etcétera), los habitantes de la unidad doméstica se ayudan entre ellos en primera instancia y en segundo lugar recurren a familiares de primer grado no corresidentes. En tercer lugar, y sólo en ciertos casos, recurren a compañeros de trabajo. Llama la atención que no establezcan relaciones de intercambio más allá del saludo con sus vecinos. Con base en esto podría plantearse que la valoración que hace la clase media respecto a la homogeneidad de la zona residencial, es un factor de delimitación frente a los otros, sobre todo 
frente a las clases bajas, y constituye una condición objetiva para la definición de un estilo de vida, que en cuanto a la interacción puede conducir al aislamiento de las unidades domésticas dentro del espacio residencial; aunque también puede hacer surgir la conformación de una identidad social y la actividad política de las clases medias, a partir del espacio urbano, proceso reciente, según lo plantea María Luisa Tarrés para el caso de la organización política de colonos de Ciudad Satélite de la Zona Metropolitana de la Ciudad de México (Loaeza y Stern [coords.], 1990). Habría que estudiar cuáles son las condiciones necesarias para que se cumpla dicho proceso, y si está ligado al tamaño de la ciudad o son otros los factores relevantes.

\section{Bibliografía}

Arizpe, Lourdes (1989), Cultura y desarrollo. Una etnografía de las creencias de una comunidad mexicana, México, unAm, Miguel Ángel Porrúa, El Colegio de México.

Bonfil Batalla, Guillermo (1991), Pensar nuestra cultura, México, Alianza Editorial.

Bordieu, Pierre (1990), Sociología y cultura, México, Grijalbo.

Bosc, Pierre y Simone Chapoulie (1981), Approches sociologiques des classes sociales, París, Profil Dossier, Hatier.

Castells, Manuel (1989), The informational City. Information Technology, Economic restructuring and the Urban-Regional Process, Gran Bretaña, Basil Blackwell editor.

Chavarría Bravo, Jorge Benjamín y Martha Consuelo Sánchez A. (1992), "Conformación del espacio urbano de la ciudad de Querétaro 19701990: agentes que intervienen", tesis de licenciatura en Geografía, México, Universidad Nacional Autónoma de México.

Douglas, Mary y Baron Isherwood (1990), El mundo de los bienes. Hacia una antropología del consumo, México, Consejo Nacional para la Cultura y las Artes, Grijalbo.

Estrella Hernández, Esperanza (1992), "Vida y costumbres de la clase media en la ciudad de Querétaro", en Memorias del Encuentro Nacional sobre Ciudades Medias, Ayuntamiento de Morelia, Michoacán.

García Peralta, Beatriz (1988), La actividad inmobiliaria en la ciudad de Querétaro: 1960-1982, Cuadernos de investigación social núm. 17, México, Instituto de Investigaciones Sociales-UNAM.

Garza, Gustavo (1992), "Impacto regional de los parques industriales", en Ciudades. Dinámica urbano-regional en los noventa, año 4, núm. 13, enero-marzo, Red Nacional de Investigación Urbana, pp. 27-37.

Giddens, Anthony (1983), La estructura de clases en las sociedades avanzadas, Madrid, Alianza Universidad (primera edición en inglés 1973).

González Gómez, Ovidio y Carlos Martner Peyrelongue (1990), "Queréta- 
ro: ciudades fragmentadas", en Ciudades. Dinámica urbano-regional en los noventa, núm. 6: Procesos Metropolitanos, abril-junio, Red Nacional de Investigación Urbana, pp. 23-30.

y Carmen Imelda González Gómez (1992), Transporte en Querétaro en el siglo $\mathrm{XX}$, Secretaría de Comunicaciones y Transportes, Instituto Mexicano del Transporte/Gobierno del estado de Querétaro.

Harvey, David (1985), The Urbanization of Capital. Studies in the History and Theory of Capitalist Urbanization, Oxford, Basil Blackwell Ltd., $239 \mathrm{pp}$.

Icazuriaga Montes, Carmen (1991), "Estudio holístico de ciudades medias. El caso de la ciudad de Querétaro", en Antropología y ciudad, México,CIESAS-UAMI (en prensa).

(1992), "Cultura urbana y cambio social", en Memorias del Encuentro sobre ciudades medias, Ayuntamiento de Morelia, Michoacán.

(1993), "Nuevas costumbres y viejos hábitos de la clase media de la ciudad de Querétaro", XV Coloquio de Antropología e Historia Regionales: ciudades provincianas de México, crisoles de cambio, Zamora, El Colegio de Michoacán (en prensa).

Loaeza, S. y Claudio Stern (coords.) (1990), Las clases medias en la coyuntura actual, México, El Colegio de México.

Leñero Otero, Luis y Ma. Estela Fernández R. (1983), Formas de vida en ciudades medias del centro de México: Morelia, Querétaro y San Luis Potosí, México, Instituto Mexicano de Estudios Sociales, A.C.

Munguía Huato, Ramón (1988), "El desarrollo urbano en la ciudad de Querétaro", en Revista Sociología, año 2, núm. 20, Verano, Querétaro, Universidad Autónoma de Querétaro, pp. 24-31.

Pincon-Charlot, Monique, Edmond Preteceille y Paul Rendu (1986), Ségrégation urbaine. Classes sociales et équipement collectifs en région parisienne, París, Editions Anthropos.

Singer, Paul (1981), Economía política de la urbanización, México, Siglo XXI Editores (primera edición en portugués 1975).

Unikel, Luis, Crescencio Ruiz Ch. y Gustavo Garza V. (1978), El desarrollo urbano de México. Diagnóstico e implicaciones futuras, México, El Colegio de México.

Whiteford, Andrew H. (1964), Two Cities of Latin America. A Comparative Description of Social Classes, Wisconsin, Doubleday Anchor Books. 